\title{
The application of malolactic fermentation process to create good-quality grape wine produced in cool-climate countries: a review
}

\author{
Małgorzata Lasik
}

Received: 13 June 2013 / Revised: 9 August 2013 / Accepted: 21 August 2013 / Published online: 14 September 2013

(C) The Author(s) 2013. This article is published with open access at Springerlink.com

\begin{abstract}
The work presents the essence of the secondary fermentation occurring in the course of grape wines production-malolactic fermentation (MLF). The selection of wine yeast and bacteria preparations, scenario of malolactic bacteria inoculation as well as control system of the process conditions are proposed to create the specific character and style of grape wines produced in cool-climate countries, in which the acidity of grape must is often significantly enhanced and the concentration of aroma compounds is considerably low. The role played by appropriately run MLF is presented, along with the advantages and disadvantages of the process, benefits, and technological drawbacks resulting from the introduction of this procedure to the vinification process. Moreover, methods to initiate and run MLF as well as interactions occurring between microorganisms used in wine production, i.e., wine yeasts from the genus Saccharomyces and wine bacteria from the genus Oenococcus, are also presented and discussed.
\end{abstract}

Keywords Grape wine $\cdot$ Malolactic bacteria .

Oenococcus oeni $\cdot$ Malolactic fermentation

\section{Winemaking in cool-climate countries}

A cool climate and potentially disadvantageous conditions for grape vine growing do not have to exclude the wine production potential of a given region, while in many countries, they have proven to promote, rather than prevent,

M. Lasik $(\bowtie)$

Department of Fermentation and Biosynthesis, Faculty of Food

Sciences and Nutrition, Poznań University of Life Sciences,

Wojska Polskiego 31, 60-624 Poznan, Poland

e-mail: lasik@up.poznan.pl grape and wine culture. For example, grapes from English vineyards with a deficit of sunshine, due to high acidity, are not suitable for the production of traditional wines; in contrast, it is acidity that provides those sparkling wines with a distinct character. In turn, severe frosts toward the end of the winemaking season in Canada have contributed to the development of highly specific ice wines. Attempts at the production of this wine specialty have been made also in other cool-climate countries such as Germany, the Czech Republic, and Austria. However, in those countries, early frosts are recorded at every several years, while in Canada (the world leader in the production of ice wine), this type of exclusive wine is produced every year [1-3].

Thus, in European countries with a cool climate, it is also possible to produce wine with an original, regional character, exceptional in the mass scale production of imported wines. However, modified and directed production technologies of such wines are required, particularly in view of the elevated acidity and weak aroma of must. An ideal solution for processing of such raw material is provided by secondary fermentation, initiated usually toward the end of alcoholic fermentation, i.e., the so-called malolactic fermentation (MLF). Reduction of acidity, enhancement of biological stability as well as modification of wine aroma and texture are primary objectives of this process [4-6]. In some countries of cool climate, the vinification process using MLF has been successfully applied for years. So far, only in countries with high public awareness of winemaking techniques, almost all red wines, most sparkling wines, and a portion of white wines are subjected to secondary fermentation (a total of $75 \%$ red wines and $40 \%$ white wines). It is estimated that incorporation of MLF into the winemaking process results in an insignificant increase in production costs, which should not be a financial burden for producers, particularly in a situation when with an 
increasing public awareness consumers are ready to pay higher prices for better-quality wine.

\section{The essence and role of MLF in winemaking process}

The primary and most significant process during wine production is ethanol fermentation, i.e., enzymatic decomposition of sugars to ethanol and $\mathrm{CO}_{2}$ under the influence of yeast activity in anaerobic conditions. Commonly used yeasts include those from the genus Saccharomyces, particularly strains such as Saccharomyces cerevisiae ssp. cerevisiae and S. cerevisiae ssp. bayanus. In the course of fermentation together with ethanol also other compounds are formed, i.e., by-products of alcoholic fermentation, having a significant effect mainly on the taste, flavor, and aroma of produced wine. These include, e.g., organic acids such as succinic, acetic, and lactic acids; higher alcohols; acetic aldehyde; esters; and glycerol [4, 7, 8].

Toward the end of ethanol fermentation, a spontaneous secondary fermentation may occur, i.e., MLF. This procedure is recommended mainly for red wines, some white wines, and certain fruit wines. This process is initiated by lactic acid bacteria from the genus Lactobacillus, Pediococcus, and Leuconoctoc. At present, the strain Oenococcus oeni (previously named Leuconostoc oenos) has been selected as the most efficient and specific to the appropriate course of MLF [5, 6, 9, 10]. This process, also called biological deacidification, consists in decarboxylation of $\mathrm{L}(-)$ malic acid to $\mathrm{L}(+)$ lactic acid as well as $\mathrm{CO}_{2}$, and $1 \mathrm{~g}$ of malic acid is converted into $0.67 \mathrm{~g}$ of lactic acid and $0.33 \mathrm{~g}(165 \mathrm{ml})$ of $\mathrm{CO}_{2}$. Malic acid, together with tartaric acid, is the basic component determining total acidity of wine. Both acids comprise over $90 \%$ total organic acids found in wine. Concentration of malic acid in grapes from a cool-climate region may be as high as $9 \mathrm{~g} / \mathrm{l}$; thus, it is crucial to reduce its content. Moreover, malic acid-dicarboxylic-more acidic in taste (as, e.g., characteristic acidity in apples) is transformed to lactic acid-monocarboxylicmilder in taste (as, e.g., acidity of dairy fermented drinks). As a result of its bioconversion, a smaller amount of the milder acid is formed and wine is additionally saturated with $\mathrm{CO}_{2}[6,11-14]$.

Another role, apart from biological deacidification, of MLF is to modify the flavor, aroma, and texture of produced wine. Bacteria $O$. oeni through biosynthesis of several metabolites such as acids, alcohols, and esters promote the removal of undesirable plant or herb aromas, at the same time enriching wine with fruit and flower aromas [6, 12, 14-17]. Moreover, a group of lactic acid bacteria used in MLF was classified as microorganism-synthesizing antimicrobial compounds called bacteriocin-like inhibitory substances (BLIS). These substances markedly reduce microbial growth, particularly other lactic acid bacteria, i.e., first of all those contributing to many quality defects of wine. Bacteriocin-like inhibitory metabolites of Oenococcus due to the narrow range of activity should not influence metabolic activity of wine yeasts. In turn, they may prove to be an effective tool in the control of lactic acid bacteria responsible for the production of metabolites deteriorating wine quality, mainly polysaccharides, diacetyl, acetoin, acetic acid, or acetaldehyde [12,13,18-21]. Another advantageous characteristic of malolactic bacteria is connected with the decomposition of undesirable by-products of alcoholic fermentation, e.g., acetaldehyde. They significantly reduce the concentration of this toxic, readily volatile compound, extremely undesirable from the sensory and health point of view. Acetaldehyde, apart from its toxic properties, also shows a high binding capacity of $\mathrm{SO}_{2}-$ an antimicrobial and antioxidative compound. Conversion of $\mathrm{SO}_{2}$ from the free to bound form (e.g., with acetaldehyde) is a significant problem in winemaking technologies requiring intensification of the sulfitation process. The application of MLF may contribute to a reduction of wine sulfitation and an effective reduction of acetaldehyde concentration [13, 20-24].

\section{Conditions for the appropriate course of MLF, benefits, and technological drawbacks}

In the case of acidic and weakly aromatic musts, the MLF process is highly desirable due to the role, which it plays in the modification of quality of the produced wine. However, in view of the difficult environmental conditions found in young wine upon the completion of alcoholic fermentation (high ethanol concentration, low temperature and $\mathrm{pH}$, low nutrient concentrations, the presence of free $\mathrm{SO}_{2}$ ) spontaneous initiation of this process is very difficult or does not occur at all $[5,6,11,12]$. Conditions required for the induction and appropriate course of MLF include initial temperature of $20-25{ }^{\circ} \mathrm{C}$ (which is rather troublesome, since at the completion of alcoholic fermentation, the temperature of young wine is much lower), while during MLF, the temperature is $18-20^{\circ} \mathrm{C}$, the content of free $\mathrm{SO}_{2}$ should be below $10 \mathrm{mg} / \mathrm{l}$, total $\mathrm{SO}_{2}$ concentration below $30 \mathrm{mg} / \mathrm{l}$, and $\mathrm{pH}$ at 3.2-3.4 [6, 11-14].

A significant role is played by the presence of nutrients such as sugar (glucose, fructose), organic acids (malic and citric acids), organic nitrogen (amino acids, peptides), vitamins (B, pantothenic acid), and minerals ( $\mathrm{Mn}, \mathrm{Mg}, \mathrm{K}, \mathrm{Na}$ ). In the case of total consumption of nutrients by yeasts during alcoholic fermentation, it is necessary to supplement young wine with sources of $\mathrm{C}, \mathrm{N}$, and $\mathrm{P}$ essential for lactic acid bacteria. Another practice is to leave wine over the lees (sediment of yeast cells) until cell autolysis. However, 
it poses a risk of undesirable metabolites being synthesised. As a result of properly conducted MLF, malic acid content may be reduced by as much as $90 \%[6,11-13,25]$.

A significant role in the accuracy course of the secondary fermentation is also played by the concentration of polyphenolic compounds [26]. For example, tannins found in high amounts in certain grape varieties, e.g., Merlot, may have a negative effect on the process of MLF. For this reason, some winemakers try to reduce their content by precipitation [26-28]. However, not all phenolic compounds pose a hazard to the growth and metabolic activity of bacteria $O$. oeni. An example of the stimulatory effect may be provided by vanillin, which in the course of vinification process is released from barrels to wine. This compound accelerates the logarithmic bacteria growth phase, which is particularly important at low doses of inoculum. Moreover, vanillin is metabolized by bacteria to compounds, which improve wine aroma [29].

An insufficiently described, but highly significant factor inhibiting MLF is connected with the presence in must of pesticide residue, substances protecting plants against undesirable microorganisms and diseases. Some research groups find that even the smallest amounts of these compounds (like cooper or dichlofluanid) can significantly disturb the course of the MLF, including its complete inhibition [30]. However, other research demonstrate very slight influence of pesticides on MLF efficiency [31, 32]. The effect of red wine MLF on the fate of seven fungicides (carbendazim, chlorothalonil, fenarimol, metalaxyl, oxadixyl, procymidone, and triadimenol) and three insecticides (carbaryl, chlorpyrifos, and dicofol) was investigated. After MLF using $O$. oeni, the concentrations of the active compounds such as chlorpyrifos and dicofol were the most significantly reduced, whereas the concentrations of chlorothalonil and procymidone diminished only slightly. The effect of these pesticides on the activity of the bacteria was also presented. Dicofol had a major inhibitory effect on the catabolism of malic acid, whereas chlorothalonil, chlorpyrifos, and fenarimol expressed only a minor effect [31]. Probably, this effect is strongly dependent on the malolactic bacteria strain, variety of fermented grapes, vinification technique used as well as the type of the used pesticide: herbicides, insecticides, and fungicide.

Cool-climate countries (Germany, Austria, Czech Republic, Poland), particularly those with limited winemaking traditions, only now are starting to introduce inoculation with lactic acid bacteria, although still a majority of winemakers rely only on spontaneous fermentation. This process is evaluated arbitrarily, mainly based on changes in wine flavor and taste. The process itself is not controlled, but rather only observed and in the case of any signs of adverse changes, young wine is immediately decanted from above the lees and it is sulfitated in order to completely stop fermentation. Such an uncontrolled process is highly risky and may cause disqualification of the produced wine as a result of accumulation of adverse metabolites of lactic acid bacteria. It may, e.g., lead to an excessive production of diacetyl, a decomposition product of citric acid. When found in wine at low concentrations, it provides pleasant, subtle nutty, caramel, and butterscotch aroma. However, at higher doses, above $1 \mathrm{mg} / \mathrm{l}$, it is responsible for less pleasant, intensive rancid flavor. At higher amounts (up to $4 \mathrm{mg} / \mathrm{l}$ ), it may be produced by spontaneous MLF bacteria, e.g., Pediococcus, while at considerably lower amounts (approximately $0.2 \mathrm{mg} / \mathrm{l}$ ) by $O$. oeni, a strain applied in MLF inocula [5, 6, 11-13, 19]. A lack of process control, mainly in terms of temperature and dominant microflora, may result in the appearance of other undesirable fermentation by-products, such as, e.g., biogenic amines, polysaccharides, acrolein, acetic acid, D-lactate, butylene glycol, acetaldehyde, or acetoin [6, 13, 20-24]. Biogenic amines are low-molecular weight organic bases formed in general in fermented food and beverages by bacterial metabolism mostly via the activity of specific amino acid decarboxylase. The most important and most often find in wine biogenic amines are histamine, tyramine, putrescine, and cadaverine followed by phenylethylamine, spermidine, spermine, agmatine, and tryptamine. The variability in quality and quantity of biogenic amines content in grape wine is explained on the basis of differences in winemaking process techniques, raw material quality, and possible microbial contamination during the whole vinification process [33-36]. It was found that some enological practices widely used to enhance wine quality, like aging of wine on the yeast lees or longer grape skin maceration, significantly increased the concentration of biogenic amines. From the other hand, the inoculation of wine with commercial malolactic starters minimized the levels of synthesized biogenic amines. This biogenic amines formation ability is usually a strain-dependent property. In general, lactic acid bacteria from the genus Lactobacillus and Pediococcus are the most known producers of biogenic amines in wines. That is why the controlled malolactic process is so important for a wine quality. Commercial malolactic starters, including prevalent $O$. oeni strains, are strictly selected for the lack of biogenic amine synthesis ability [11, 13, 14, 37, 39]. Enhanced concentration of biogenic amines can cause a toxic effect on human health like release of adrenaline, provoke gastric acid secretion, increase cardiac output, migraine, tachycardia, increase blood sugar level, and higher blood pressure [40]. However, there is worth to mention that there are also reports about malolactic bacteria able to degrade biogenic amines in wine through the production of amine oxidase enzymes. The greatest biogenic amine-degrading ability was exhibited by strains belonging to Lactobacillus and Pediococcus groups [38]. This is very interesting and very 
rarely observation because most often the biogenic amines are produced exactly by these two groups of bacteria. So it confirms that selected lactic acid wine-associated bacteria can help to improve the quality of wine like in this case and to reduce biogenic amines concentration. Wine industry is focused now very intensive for absolute elimination of biogenic amines from wines. Many countries have established limits for this compound's content in wines and other alcohol drinks and spirits so the determination in the reduction in biogenic amines concentration is actually sill more noticeable.

An other example of a highly undesirable by-product is also ethyl carbamate (urethane). It is formed by enzymatic deamination of arginine, resulting in the production of urea. Ethanol, entering into the reaction with urea, is converted into ethyl carbamate. Factors promoting the formation of these compounds include low $\mathrm{pH}$, low alcohol content, and excessive keeping of wine over lees. This compound, although found naturally in many fermented products (alcoholic beverages, bread, cheese, yoghurts, sauerkraut), was classified by the European Parliament (C6-0267/2006) to be a class II carcinogen, next to, e.g., bromo ethylene or acrylamide [41, 42]. A trend toward a reduction in admissible concentration threshold for this compound in food should be an incentive for the winemaking industry to apply techniques facilitating the inhibition of its biosynthesis.

Malolactic fermentation process is still relatively little known and insufficiently described, particularly in terms of the diversity and concentrations of accumulated secondary metabolites. This is probably caused by the high specificity and variability of the process dependent on the used microorganisms, fermentation conditions as well as character of must to be used in the production of wine. Problems with the appropriate course of MLF have contributed to an increased interest of winemakers in pure cultures of MLF bacteria, which do not cause such multifaceted adverse changes and facilitate more effective process control and management.

\section{Principle of MLF initiation and management}

Malolactic fermentation in wine may occur spontaneously, as a result of action of the natural wine microflora, but it is a random process, since severe environmental conditions may delay or completely stock MLF [6, 11-14]. For this reason, a continuous progress is observed in the selection of bacterial strains and in the production technologies of wine starter cultures, resulting in greater control over the process $[5,8-10,13,43]$. Still there is a risk of failure in the induction and a proper course of fermentation and wines may be spoiled by undesirable microorganisms, such as acetic acid bacteria, certain strains of lactic acid bacteria or Zygosaccharomyces, Brettanomyces, and Dekkera yeast species [44, 45].

Selection of strains for wine inoculation was initially based mainly on conventional tests, determining survival rates of bacteria in wine environment and monitoring of malic acid bioconversion to lactic acid. At present, knowledge on the physiology of $O$. oeni under stress conditions is used to create tools, which is based on the molecular and physiological aspects that facilitate more precise characteristics of strains. Studies are being conducted on the activity of intracellular enzymes responsible for the metabolism of malic acid and production of ATPase, i.e., the two factors having the decisive effect on the acidophilic character of $O$. oeni bacteria $[6,9,10,12,19,43,46,47]$.

The moment of initiating MLF is dependent on the applied bacterial cultures or yeast metabolism products [7, 11, 14]. Theoretically, the process may be initiated at four different moments during the vinification process:

\section{Before alcoholic fermentation}

Applicable only in the production of white wine, using a strain Lactobacillus plantarum, characterized by a very low tolerance to alcohol. An optimal $\mathrm{pH}$ in this case is max. 3.4. In such a variant of bacterial inoculation, the production of lactic acid at the expense of sugars is observed and for a short time of bacterial life, malic acid is not completely reduced. In this technique, yeasts are added to completely clarified must 2 days after bacterial inoculation. Bacteria should be supplied at a very high concentration to prevent their intensive multiplication as well as competition with yeasts for available nitrogen and other nutrient components. In such case, also different profile of secondary metabolites can be created. There is a risk that undesirable compounds may be produced, which detract from the quality and acceptability of the produced wines [48, 49].

\section{Simultaneous alcoholic and MLF}

Malolactic fermentation is difficult to run in certain wines, mainly due to the strongly inhibitory action of ethanol and acidity in wines. In turn, the establishment of advantageous conditions for lactic acid bacteria exposes wine to spoilage by other microorganisms. A simultaneous ethanol and MLF may contribute to a more efficient bioconversion of malic to lactic acid. A particular role is played by the application of elevated temperature found during alcoholic fermentation, as well as low concentrations of ethanol and a higher nutrient content in grape must in comparison with young wine. Moreover, wines obtained as a result of simultaneous fermentation are immediately ready to direct procedures, such as racking, clarification, and sulfitation, which 
enhances microbial stability and process yield. Moreover, wines with co-inoculations tended to have higher concentration of ethyl and acetate esters [7, 49-51].

Despite considerable interest in this technique, its application is still limited. There are apprehensions concerning the deterioration of wine quality, connected with a lack of sufficient data on this variant of inoculation. Growth of lactic acid bacteria in must may stop alcoholic fermentation before complete consumption of sugar, and acetic acid may be synthesized in young wine at an elevated concentration, making it unsuitable for consumption [50].

Prior to completion of alcoholic fermentation

Inoculation with bacteria $O$. oeni takes place at the last third of alcoholic fermentation, thanks to which fermentation heat may be utilized and limit the risk of wine storage without $\mathrm{SO}_{2}$. However, there is a risk of stocking the alcoholic fermentation before it is completed [7, 49].

\section{After alcoholic fermentation}

A moment advantageous for malolactic bacterial inoculation is quenched fermentation, when the concentration of residual sugar does not exceed $4 \mathrm{~g} / \mathrm{l}$, while total concentration of sulfur dioxide is max. $30 \mathrm{mg} / \mathrm{l}$. Although at such environmental conditions there is the lowest risk of error, the initiation of MLF after the completion of ethanol fermentation is more difficult because of relatively row conditions (low temperature, enhanced $\mathrm{SO}_{2}$ concentration, reduced nutrient compounds). Most often, this scenario is applied in the vinification process, especially when malolactic bacteria inoculation is performed. If no commercial starter cultures are planned to use, some operations for spontaneous malolactic process induction, like enhanced temperature, pure sulfitation, and microaeration, need to be done $[7,49]$.

\section{Interactions between yeasts and bacteria}

Currently conducted enological research focuses on the explanation of interactions between yeasts Saccharomyces and bacteria Oenococcus, particularly the essence of competition for nutrients as well as the type and character of the synthesized metabolites with potential stimulatory and/ or inhibitory properties [21, 43, 52-54].

\section{Inhibition of bacteria $O$. oeni by yeasts $S$. cerevisiae}

Ethanol is the primary product of fermentation synthesized by yeasts. Its concentration influences bacterial cells' condition and thus also on MLF course. Ethanol at an amount over $8 \% \mathrm{v} / \mathrm{v}$ considerably reduces the kinetic of bacterial growth, although it does not reduce the ability to metabolize malic acid. Thus, it is particularly dangerous in these winemaking processes, where the initial content of bacterial biomass is too low for the bioconversion of malic acid. Ethanol in combination with other inhibitors may effectively inhibit MLF [53].

Sulfur dioxide is a chemical compound with a considerable importance for wine production, and for this reason, it is a subject of interest for many researchers. Yeast $S$. cerevisiae is capable of producing $\mathrm{SO}_{2}$ at varying amounts, depending on an applied strain. Most of them produce it at less than $30 \mathrm{mg} / \mathrm{l}$ wine; however, there are also strains that are capable of producing this compound at more than $100 \mathrm{mg} / \mathrm{l}$ wine $[21,55]$. Free sulfur dioxide at a concentration of $15 \mathrm{mg} / \mathrm{l}$ wine at $\mathrm{pH}$ below 3.5 considerably reduces the viability of cells and their capacity to proliferate. Additionally, the content of molecular $\mathrm{SO}_{2}$ at an amount of over $0.5 \mathrm{mg} / \mathrm{l}$ wine causes an inhibition of bacterial growth. In combination with other inhibitors, sulfur dioxide may at the same time limit the growth of bacteria and their ability for malic acid fermentation [24, 55, 56].

Apart from the above-mentioned compounds, yeasts are capable of generating medium-chain fatty acids. These compounds have the properties to inhibit the growth of bacterial cells, but also cause a reduction of catabolic capacity in relation to malic acid. However, this is closely related with the type and the concentration of medium-chain acid in the medium. It was shown that a content up to $10 \mathrm{mg}$ decanoid acid per 11 wine inhibits the growth of bacterial cells while a content of over $30 \mathrm{mg} / \mathrm{l}$ wine for the same acid is a lethal dose for bacteria. It is additionally known that the presence of decanoid and lauronic acids at 4 and $0.5 \mathrm{mg}$ per 11 wine, respectively, inhibits MLF. What is more, it was also detected that a simultaneous addition of hexanoic, octanoic, and decanoid acids has a greater inhibitory effect than any of the acids separately [53]. The inhibitory ability of medium-chain fatty acids is dependent on $\mathrm{pH}$ of wine. This is connected with the fact that fatty acids undissociated at low $\mathrm{pH}$ more readily penetrate through cell membranes of bacteria. Inside the cell hydrogen is detached from the carboxyl group, causing intracellular acidification and dispersion of the transmembrane gradient. Mediumchain fatty acids in combination with low $\mathrm{pH}$ and ethanol are able to reduce the activity of intracellular enzymes, e.g., ATPase, which are used in the metabolic pathway of malic acid [47, 57].

One of the causes for the inhibition of MLF may be also associated with the production of intracellular cation proteins. At present, nothing can be said on the structure of these compounds, since they could not be isolated. However, on the basis of research, it was stated that in wines subjected to heating, inhibition of bacteria did not take 
place. This leads us to infer that proteins could be the inhibitors, which at an elevated temperature were denatured [54].

Another cause for the inhibition of bacteria by yeasts may be connected with the depletion of nutrients. It was stated that, e.g., a particularly adverse for the activity of MLF bacteria is posed by amino acid deficit in the medium. Their depletion during alcoholic fermentation delays the onset of MLF up to the time of repeated increase in their concentration as a result of autolysis of yeast cells $[8,21$, 58]. This in turn has to be closely controlled particularly due to the risk of excessive increase in urea concentration in wine-a precursor of carcinogenic urethane (ethyl carbamate) $[41,42]$.

\section{Stimulation of bacteria $O$. oeni by yeasts $S$. cerevisiae}

Yeasts do not always have a negative effect on growth and metabolic activity of malolactic bacteria. The commonly applied winemaking practice, such as keeping wine over lees, may have an advantageous effect on the condition of bacteria responsible for MLF. This phenomenon is caused by lysis of yeast cells in lees. This causes the release of many nitrogen compounds to the young wine, such as, e.g., amino acids, peptides, and polypeptides, required for growth and appropriate activity of bacterial cells. It is also known that the best properties stimulating the growth of $O$. oeni are found in peptides with molecular mass below 1,000 Da. However, proteins released from decomposed yeast cell walls, with a molecular mass above $12 \mathrm{kDa}$, may induce the production of aminopeptidase in bacterial cells [59].

Mannoproteins are another example of compounds secreted by yeasts, exhibiting stimulatory properties for malolactic bacteria. Firstly, these compounds may adsorb medium-chain fatty acids, thanks to which they contribute to detoxication of the environment. Secondly, mannoproteins stimulate bacteria to produce hydrolytic enzymes [11, $13,21,60,61]$.

Inhibition of yeasts $S$. cerevisiae by bacteria $O$. oeni

The inhibitory effect of malolactic bacteria on yeasts during MLF in wines is observed when inoculation with bacteria or induction of the spontaneous MLF occur no later than before the completion of alcoholic fermentation [50].

A major cause of inhibition of yeast fermentation ability is connected with the consumption of nutrients by bacteria and excessive production of acetic acid. This resulted in an acceleration of yeast cell death, which may cause an incomplete bioconversion of sugars in grape must [21, 50]. Moreover, MLF bacteria are capable of producing an extracellular enzyme beta-1,3-glucanase, which may cause decomposition of cell walls both in dead and live yeast cells [21]. Additionally, a mechanism was observed of bacterial biosynthesis of BLIS and their significant effect on the control of process microflora as well as the microbial stability of the final product, i.e., wine [18].

Applying different inoculation protocols and vinification techniques may offer microbiological, technological, and sensorial advantages especially in acidic, cool-climate grape musts. However, the success of vinification also depends on the selection of suitable yeast-bacteria combination $[11,13,21,49]$.

Acknowledgments The author (Malgorzata Lasik) has received research grant from the State Committee for Scientific Research (Poland) - project No NN312 206036.

\section{Conflict of interest None.}

Compliance with Ethics Requirements This article does not contain any studies with human or animal subjects.

Open Access This article is distributed under the terms of the Creative Commons Attribution License which permits any use, distribution, and reproduction in any medium, provided the original author(s) and the source are credited.

\section{References}

1. Jones GV, White MA, Cooper OR, Storchmann K (2005) Climate change and global wine quality. Clim Chang 73:319-343

2. Reisch BI, Pool RM, Peterson DV, Martens MH, Henick-Kling T (1993) Wine and juice grape varieties for cool climates. Cornell Cooperative Extension Publication, Information Bulletin 233, Cornell University, Ithaca, NY, pp 9-18

3. Kenny GJ, Harrison PA (1992) The effects of climate variability and change on grape suitability in Europe. J Wine Res 3:163-183

4. Viljakainen SK, Laakso SV (2002) Acidity reduction in northern region berry juices by the malolactic bacterium Oenococcus oeni. Eur Food Res Technol 214:412-417

5. Maicas S (2001) The use of alternative technologies to develop malolactic fermentation in wine. Appl Microbiol Biotechnol 56:35-39

6. Versari A, Parpinello GP, Cattaneo M (1999) Leuconostoc oenos and malolactic fermentation in wine: a review. J Ind Microbiol Biotechnol 23:447-455

7. Abrahamse CE, Bartowsky EJ (2012) Timing of malolactic fermentation inoculation in Shiraz grape must and wine: influence on chemical composition. World J Microbiol Biotechnol 28:255-265

8. Kato S, Ishihara T, Hemmi H, Kobayashi H, Yoshimura T (2011) Alterations in D-amino acid concentrations and microbial community structures during the fermentation of red and white wines. J Biosci Bioeng 111:104-108

9. Lopez I, Tenorio C, Zarazaga M, Dizy M, Torres C, Ruiz-Larrea F (2007) Evidence of mixed wild populations of Oenococcus oeni strains during wine spontaneous malolactic fermentations. Eur Food Res Technol 226:215-223

10. Costello PJ, Morrison RH, Lee RH, Fleet GH (1983) Numbers and species of lactic acid bacteria in wines during vinification. Food Technol Aust 35:14-18 
11. Davis CR, Wibowo D, Eschenbruch R, Lee TH, Fleet GH (1985) Practical implications of malolactic fermentation in wine. J Appl Bacteriol 63:513-521

12. Davis CR, Wibowo DJ, Lee TH, Fleet GH (1986) Growth and metabolism of lactic acid bacteria during and after malolactic fermentation of wines at different pH. Appl Environ Microbiol 51:539-545

13. Henick-Kling T (1993) Malolactic fermentation. In: Fleet GH (ed) Wine microbiology and biotechnology. Harwood Academic Publishers, Switzerland

14. Henick-Kling T (1995) Control of malo-lactic fermentation in wine: energetics, flavour modification and methods of starter culture preparation. J Appl Bacteriol Symp Suppl 79:29-37

15. Hernandez-Orte P, Lapena AC, Escudero A, Astrain J, Baron C, Pardo I, Polo L, Ferrer S, Cacho J, Ferreira V (2009) Effect of micro-oxygenation on the evolution of aromatic compounds in wines: malolactic fermentation and ageing in wood. Food Sci Technol 42:391-401

16. Izquierdo Canas PM, Garcia Romero EG, Gomez Alonso S, Palop Herreros MLL (2008) Changes in the aromatic composition of Tempranillo wines during spontaneous malolactic fermentation. J Food Compos Anal 21:724-730

17. Maicas S, Gil JV, Pardo I, Ferrer S (1999) Improvement of volatile composition of wines by controlled addition of malolactic bacteria. Food Res Int 32:491-496

18. Yurdugul S, Bozoglu F (2002) Studies on an inhibitor produced by lactic acid bacteria of wines on the control of malolactic fermentation. Eur Food Res Technol 215:38-41

19. Costello PJ, Henschke PA, Markides AJ (2003) Standardized methodology for testing malolactic bacteria and wine yeast compatibility. Aust J Grape Wine Res 9:127-137

20. Osborne JP, de Ordona RM, Pilone GJ, Liu SQ (2000) Acetaldehyde metabolism by wine lactic acid bacteria. FEMS Microbiol Lett 191:51-55

21. Alexandre H, Costello PJ, Remize F, Guzzo J, Guilloux-Benatier M (2004) Saccharomyces cerevisiae-Oenococcus oeni interactions in wine: current knowledge and perspectives. Int J Food Microbiol 93:141-154

22. Osborne JP, Dube Morneau A, de Orduna RM (2006) Degradation of free and sulfur-dioxide-bound acetaldehyde by malolactic lactic acid bacteria in white wine. J Appl Microbiol 101: 474-479

23. Jackowetz JN, Dierschke S, de Orduna RM (2011) Multifactorial analysis of acetaldehyde kinetics during alcoholic fermentation by Saccharomyces cerevisiae. Food Res Int 44:310-316

24. Jackowetz JN, de Orduna RM (2012) Metabolism of $\mathrm{SO}_{2}$ binding compounds by Oenococcus oeni during and after malolactic fermentation in white wine. Int J Food Microbiol 155:153-157

25. Campo G, Berregi I, Santos JI, Duenas M, Irastorza A (2008) Development of alcoholic and malolactic fermentations in highly acidic and phenolic apple musts. Bioresour Technol 99:2857-2863

26. Cabrita MJ, Torres M, Palma V, Alves E, Patao R, Costa Freitas AM (2008) Impact of malolactic fermentation on low molecular weight phenolic compounds. Talanta 74:1281-1286

27. Garcia-Ruiz A, Bartolome B, Martinez-Rodriguez AJ, Pueyo E, Martin-Alvarez PJ, Moreno-Arribas MV (2008) Potential of phenolic compounds for controlling lactic acid bacteria in wine. Food Control 19:835-841

28. Moreno-Arribas MV, Gomez-Cordoves C, Martin-Alvarez PJ (2008) Evolution of red wine anthocyanins during malolactic fermentation, postfermentative treatment and ageing with lees. Food Chem 109:149-158

29. de Revel G, Bloem A, Augustin M, Lonvaud-Funel A, Bertrand A (2005) Interaction of Oenococcus oeni and oak wood compounds. Food Microbiol 22:569-575
30. Vidal MT, Poblet M, Constanti M, Bordons A (2001) Inhibitory effect of copper and dichlofluanid on Oenococcus oeni and malolactic fermentation. Am J Enol Vitic 52:223-229

31. Ruediger GA, Pardon KH, Sas AN, Godden PW, Pollnitz AP (2005) Fate of pesticides during the winemaking process in relation to malolactic fermentation. J Agric Food Chem 53:3023-3026

32. Cabras P, Angioni A, Garau VL, Pirisi GA, Madau G, Emonti G (1999) Pesticides in fermentative process of wine. J Agric Food Chem 47:3854-3857

33. Lonvaud-Funel A (2001) Biogenic amines in wines: role of lactic acid bacteria. FEMS Microbiol Lett 199:9-13

34. Beneduce L, Romano A, Capozzi V, Lucas P, Barnafon L, Bach B, Vuchot P, Grieco F, Spano G (2010) Biogenic amine in wines. Ann Microbiol 60:573-578

35. Anli RE, Bayram M (2009) Biogenic amines in wines. Food Rev Int 25:86-102

36. Ancin-Azpilicueta C, Gonzalez-Marco A, Jimenez-Moreno N (2008) Current knowledge about the presence of amines in wine. Crit Rev Food Sci Nutr 48:257-275

37. Martin-Alvarez PJ, Marcobal A, Polo C, Moreno-Arribas MV (2006) Influence of technological practices on biogenic amine contents in red wines. Eur Food Res Technol 222:420-424

38. Garcia-Ruiz A, Gonzalez-Rompinelli EM, Bartolome B, Moreno-Arribas MV (2011) Potential of wine-associated lactic acid bacteria to degrade biogenic amines. Int J Food Microbiol 148:115-120

39. Smit AY, du Toit M (2013) Evaluating the influence of malolactic fermentation inoculation practices and ageing on lees on biogenic amine production in wine. Food Bioprocess Technol 6:198-206

40. Caston JC, Eaton CL, Gheorghui BP, Ware LL (2002) Tyramine induced hypertensive episodes, panic attack in hereditary deficient monoamine oxidase patients: case report. JSC Med Assoc 98:187-192

41. Uthurry CA, Suarez Lepe JA, Lombardero J, Garcia Del Hierro JR (2006) Ethyl carbamate production by selected yeasts and lactic acid bacteria in red wine. Food Chem 94:262-270

42. Masque MC, Soler M, Zaplana B, Franquet R, Rico S, Elorduy X, Puig A, Bertran E, Capdevila F, Palacios AT, Romero SV, Heras JM, Krieger-Weber S (2011) Ethyl carbamate content in wines with malolactic fermentation induced at different points in the vinification process. Ann Microbiol 61:199-206

43. Torriani S, Felis GE, Fracchetti F (2011) Selection criteria and tools for malolactic starters development: an update. Ann Microbiol 61:33-39

44. Loureiro V, Malfeito-Ferreira M (2003) Spoilage yeasts in the wine industry. Int J Food Microbiol 86:23-50

45. Bartowsky EJ (2009) Bacterial spoilage of wine and approaches to minimize it. Lett Appl Microbiol 48:149-156

46. Terrada N, Orduna RM (2009) Determination of the essential nutrient requirements of wine-related bacteria from the genera Oenococcus and Lactobacillus. Int J Food Microbiol 133:8-13

47. Tourdot-Marchal R, Fortier L, Guzzo J, Lee B, Divies Ch (1999) Acid sensitivity of neomyicn-resistant mutants of Oenococcus oeni: a relationship between reduction of ATPase activity and lack of malolactic activity. FEMS Microbiol Lett 178:319-326

48. Barrajón-Simancas N, Giese E, Arévalo-Villena M, Úbeda J, Briones A (2011) Amino acid uptake by wild and commercial yeasts in single fermentations and co-fermentations. Food Chem 127:441-446

49. Knoll C, Fritsch S, Schnell S, Grossmann M, Krieger-Weber S, du Toit M, Rauhut D (2012) Impact of different malolactic fermentation inoculation scenarios on Riesling wine aroma. World $\mathrm{J}$ Microbiol Biotechnol 28:1143-1153

50. Jussier D, Dube Morneau A, de Orduna RM (2006) Effect of simultaneous inoculation with yeast and bacteria on fermentation 
kinetics and key wine parameters of cool-climate Chardonnay. Appl Environ Microbiol 72:221-227

51. Rossouw D, Du Toit M, Bauer FF (2012) The impact of co-inoculation with Oenococcus oeni on the transcriptome of Saccharomyces cerevisiae and on the flavor-active metabolite profiles during fermentation in synthetic must. Food Microbiol 29:121-131

52. Arnink K, Henick-Kling T (2005) Influence of Saccharomyces cerevisiae and Oenococcus oeni strains on successful malolactic conversion in wine. Am J Enol Vitic 56:228-237

53. Nehme N, Mathieu F, Taillandier P (2008) Quantitative study of interactions between Saccharomyces cerevisiae and Oenococcus oeni strains. J Microbiol Biotechnol 35:685-693

54. Comitini F, Ferretti R, Clementi F, Mannazzu I, Ciani M (2005) Interactions between Saccharomyces cerevisiae and malolactic bacteria: preliminary characterization of a yeast proteinaceous compounds active against Oenococcus oeni. J Appl Microbiol 99:105-111

55. Sico MA, Bonomo MG, Salzano G (2008) Isolation and characterization of Oenococcus oeni from Aglianico wine. World J Microbiol Biotechnol 24:1829-1835
56. Reguant C, Carrete R, Constanti M, Brodans A (2005) Population dynamics of Oenococcus oeni strains in a winery and the effect of $\mathrm{SO}_{2}$ and yeast strains. FEMS Microbiol Lett 246:111-117

57. Guerrini S, Bastianini A, Granchi L, Vincenzini M (2002) Effect of oleic acid on Oenococcus oeni strains and malolactic fermentation in wine. Curr Microbiol 44:5-9

58. Osborne JP, Edwards CG (2006) Inhibition of malolactic fermentation by Saccharomyces cerevisiae during alcoholic fermentation under low- and high nitrogen conditions: a study in synthetic media. Aust J Grape Wine Res 12:69-78

59. de Narda MCM, Farias ME, Moreno-Arribas V, Pueyo E, Polo MC (1999) Proteolytic effect of Oenococcus oeni on the nitrogenous macromolecular fraction of red wine. FEMS Microbiol Lett $174: 41-47$

60. Guilloux-Benatier M, Guerreau J, Feuillat M (1995) Influence of initial colloid content on yeast macromolecules production and on the metabolism of wine microorganisms. Am J Enol Vitic 46:486-492

61. Caridi A (2006) Enological functions of parietal yeast mannoproteins. Antonie Van Leeuwenhoek 89:417-422 